\title{
Work-life balance: The female cardiothoracic surgeon's perspective
}

\author{
Mara B. Antonoff, MD, ${ }^{\mathrm{a}}$ and Lisa M. Brown, $\mathrm{MD}^{\mathrm{b}}$
}

\footnotetext{
From the ${ }^{\mathrm{a}}$ University of Texas MD Anderson Cancer Center, Houston, Tex; and ${ }^{\mathrm{b}}$ University of California, Davis Medical Center, Sacramento, Calif.

Disclosures: Authors have nothing to disclose with regard to commercial support.

Received for publication June 30, 2015; revisions received Aug 9, 2015; accepted for publication Sept 7, 2015; available ahead of print Oct 15, 2015.

Address for reprints: Mara B. Antonoff, MD, 1400 Pressler St, Unit 1489, Houston, TX 77030 (E-mail: mbantonoff@mdanderson.org).

J Thorac Cardiovasc Surg 2015;150:1416-21

$0022-5223 / \$ 36.00$

Copyright (c) 2015 by The American Association for Thoracic Surgery

http://dx.doi.org/10.1016/j.jtevs.2015.09.057
}

The American Board of Thoracic Surgery (ABTS) certified its first women as diplomats in 1961, with the number climbing to 10 by the year 1980 . However, during the ensuing 35 years, the presence of women in the field of cardiothoracic surgery has grown dramatically. As we mark the 30th anniversary of the formation of the Women in Thoracic Surgery, our cohort of double-X chromosomes has climbed the ranks, made waves, and achieved positions of prominence in cardiothoracic surgery. ${ }^{1}$ However, despite these strides, as of 2015, women account for only approximately $3 \%$ of the total number of ABTS diplomats ever certified and comprise a small minority of practicing cardiothoracic surgeons. ${ }^{2}$ This issue carries global significance, as female representation among thoracic surgeons in Canada and Europe is similar to the gender distribution in the United States.

Through professional networking, mutual support, and committed advocacy from male sponsors and major thoracic professional organizations, women in thoracic surgery have seized numerous opportunities to achieve professional advancement. Although the prospects for women in this field have exploded in recent years, ongoing challenges and tribulations have not vanished. Certainly, it is true that we all have chosen a unique field, full of stressors and uphill battles, regardless of one's gender. In traversing a long and arduous career path, individuals may face a variety of adversities, related to financial stressors, social support, racial and religious inequities, and barriers related to sexual preferences. Even without any specific barriers, we recognize that all of our colleagues in this specialty have faced formidable challenges and demonstrated feats of endurance, courage, and compassion to join this very special field. However, we contend that there are some particular aspects of identifying oneself as both "woman" and "cardiothoracic surgeon" that bring forth a set of experiences that may be unique; we also would argue that carrying these two, previously considered oxymoronic identifiers, brings the bearer access to a world of personal and professional joy, pride, and satisfaction.

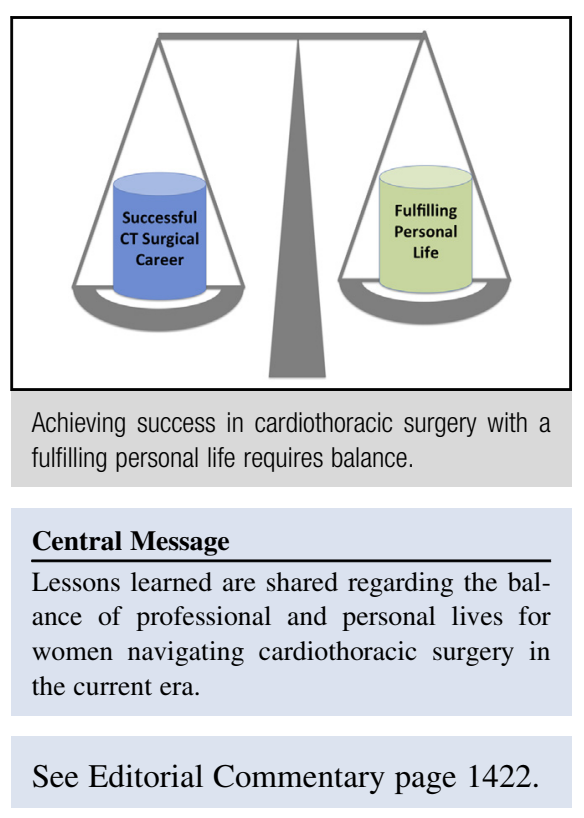

First and foremost, we'd like to dissuade any generalizations about women in this field, who they must be, or the choices that they must make. True, many of the current women in cardiothoracic surgery have dealt with situations that generally fall into 1 of 2 categories, which are dually represented by the authors of this article. In order to succeed in this competitive and challenging career, some of us has put our training and education first, persevering down a long road that may be lonely at times, and not always by choice. Others attempt to travel down this road having already embarked upon marriage and parenthood, recognizing that the paths of "work" and "home" will not likely merge, but praying that they will at least wind in parallel directions. These are our perspectives-2 women of upper Midwestern origin, honored by the outstanding training that we have received and the certification with which we have been bestowed, and thrilled at the prospects of our budding careers. One of us has functioned with both the advantages and drawbacks of independence, with parental and sibling support, but also with the stressors and liberty that come from living alone. The other of us has had all of the pleasure and anxieties that accompany life with a career-oriented husband, 2 school-aged children, and a third child on the way. We have both had an abundance of consequences, both positive and negative, from the collision of our life and career choices. Here, we offer what we have gained along the ride. In this article, we look back on the ways in which our training and early 
careers have affected our personal lives and the ways in which our lifestyles have impacted our careers. We share some of our perspectives regarding the delicate balance of professional and personal lives for women navigating this field in the current era, along with some of our lessons learned. We do not profess to be experts, and we certainly recognize that we have not made the sacrifices of the women who preceded us, who made our careers possible. We simply hope to share the ideas and thoughts of 2 women grateful to be a part of this prestigious club, trying to make it all work.

\section{IMPACT OF A THORACIC SURGICAL CAREER ON PERSONAL LIFE}

\section{Single Woman's Perspective}

As I completed my general surgery training, knowing how much time and effort that took, my parents asked me if it would get easier from that point onward. I was well aware of what I had signed up for, and I explained to them that although some fellowships are less demanding than residency, cardiothoracic surgery training would be the most-intense 2 years of my life. Midway through residency, I dedicated 2 years to clinical research, and for the first time in my life, had some time and money at the same time (and was well rested). I began competing in triathlons, took weekend trips to Tahoe (Calif), and became a wine enthusiast; in doing so, I made friendships with people that were not in the field of medicine. I had a life.

As I moved on to my final general surgery years, limited time was available to maintain these outside interests, and even less time once I started cardiothoracic surgery training. In completing my fellowship, my world suddenly became a lot smaller and consisted of whatever and whoever was in the hospital. Fortunately, I worked with a phenomenal group of people that made the training easier, as they became my makeshift family for 2 years. At the end of the day, however, in a sliver of free time, I would have enjoyed hanging out with my co-fellows. Yet most of them were married with children, and I completely understand that justifying going out to dinner with your co-fellows is difficult when they get to see you more than your own family does.

Most of us choose the training program and job position that suit us best; we then uproot ourselves, and move away from family, friends, and familiarity. A huge advantage to being single is that you control your own destiny; making your rank list and choosing a job are solely up to you. However, no built-in support system relocates with you. This adjustment can be difficult, but I am fortunate to have parents who not only supported me every step of the way, but also raised me to be confident and independent, which has paid dividends with every professional transition I have made.
Throughout my education and training, I have met many fantastic people, but they are scattered throughout the United States. In the era of social media and smartphones, we tend to feel better connected and tuned into the lives of our friends and family, but I would argue that without face-to-face interactions, it feels like an insulated existence. People are always a phone call away, but with my rigorous schedule during training, I became a poor conversationalist, as I was not up to date with current events. My nonmedical friends could endure only so much "shop talk"; in some ways, I did not want to hear about their lives, because it crystallized what I was missing. However, this lack of control is specific to training, and as I have moved on to a faculty position, I now have more control over my time and am in closer contact with friends and family.

Everything I have discussed so far is additionally true for single male cardiothoracic surgeons, with one important difference. For the most part, all cardiothoracic trainees are in the same boat. The training is exhausting, but exhilarating; developing a skillset that enables you to function under suboptimal circumstances is important. Clearly, for the rest of our careers, some patients will develop complications requiring high-level, expeditious action, unlikely to occur after a full night's sleep. Cardiothoracic surgeons who train fellows have the huge responsibility of ensuring that each trainee becomes a safe, competent surgeon in the allotted time frame. For 2 or 3 years, each trainee is under a microscope and the ensuing constructive criticism is critical to becoming the best surgeon possible.

Unfortunately, a fair amount of destructive criticism remains, to which neither male nor female trainees are immune. I eagerly signed up for this intense training paradigm, but what I did not sign up for were comments directed at me because I am a woman. During one case, I was performing a particular technique inaccurately, and rather than receiving instruction on how to do it right, I was asked: "Are you sure you want to be a cardiothoracic surgeon? Because I can sign you up for nursing school." When I shared this experience with my male counterparts, they informed me that they had not encountered any similar experience. Those situations (thankfully, not many of them occurred) triggered anger and frustration, which required extra energy to overcome and to refocus myself on the task at hand. In a survey of 10 women academic surgeon leaders (chair, center director, surgeon-in-chief, or program director), $80 \%$ reported gender inequity as a major obstacle in their career. ${ }^{4}$ When in their careers this had occurred was unclear, but overall, much movement in the right direction has taken place in terms of gender equity during the past several decades. However, to truly even the playing field for not just women and men, but surgeons of all races, religions, and sexual orientations, interactions such as the one I experienced need to cease entirely. 
No discussion of the impact of career on personal life would be complete without including the topic of dating. Many studies of the work-life balance of surgeons focus on differences between women and men. Most publications are from the field of plastic surgery, in which more than 700 women are members of the American Society of Plastic Surgeons, representing approximately $10 \%$ of all members. In that field, $35.3 \%$ of women surgeons were found to be unmarried, compared with only $12.5 \%$ of men. Moreover, $43 \%$ of women had no children, compared with $12.4 \%$ of men. ${ }^{5}$ For women who want to pursue a career in surgery, as well as get married or have children, these statistics can be daunting. I mentor many young women, and each of them asks about the ability to "have it all." The obvious challenge of dating during training is the minimal amount of time available to socialize and meet people; when I was able to escape the trenches, my first instinct was to take a nap, rather than to get dressed up for a night on the town. Even when I did muster the energy to scrape myself off the couch and go out, I was not at my best. In fact, if I had taken a good look at myself, I would have checked my own hematocrit. As I look back on pictures from my fellowship, I was so exhausted that I looked like I needed a blood transfusion (or at the very minimum, some vitamin D). This situation improves once the fellowship period is over and you are able to regain more control over your time.

That's just my side of the dating story; during training, I could understand how someone with better work-life balance (which was just about everybody else) would not be interested in dating me, someone who should perhaps have had her mail forwarded to the hospital. Moreover, attitudes vary toward women who pursue a career in surgery. I remember being told by my mentor in medical school, a woman trauma surgeon, that my decision to become a surgeon would make a negative impression on many people, and she was right.

I was at the gym one day, and as I shared my excitement about my being matched into the University of California, San Francisco general surgery program, one man said: "You must not want to get married and have children." To which I replied: "No, I just said I matched into the general surgery program at UCSF. I didn't know we were talking about marriage and family." If I were a man, I do not think the same assumption would have been made. Fast-forward 7 years to my chief resident year in San Francisco. I was waiting in line at my favorite sandwich shop when I overheard a conversation among the 3 people in front of me: a couple and their single male friend. The male friend was a physician assistant, enthusiastic about his new position as a first assist in the operating room. The couple congratulated him and said, "Exciting, maybe you can meet a good-looking, smart woman surgeon." To which he replied: "No way, then I would see first-hand what she does everyday and would have a hard time being a man for her when she comes home at the end of the day." I have always suspected that a subset of men have this mentality; the interaction I witnessed confirmed it. In my experience, the higher you climb on the academic ladder as a woman, the smaller the pool of "eligible" men becomes. In contrast, I think that the opposite is true for men as they ascend the ranks.

\section{Wife and Mother's Perspective}

From the viewpoint of a married mother of 2 with a third child on the way, it would be complete and utter dishonesty to say that my career has not had an impact on my personal life. It has impacted it tremendously. My career path has had monumental consequences on the day-to-day lives of my husband and children, with long-lasting effects on my family relationships. In attempts to minimize the sacrifices forced onto those whom I love the most, it has also meant that my personal life has, at times, been restricted to nothing more than work and a meager attempt at being a family member (ie, forget all thoughts about having friendships, maintaining a healthy level of exercise, or washing my hair on a semi-regular basis). While the effects of my job on the rest of my life have, without a doubt, intermitttently filled my mind with worry and my heart with guilt, I would be sorely remiss to deny that my career has had very important positive results upon everything else I have experience in life.

I will state one utter truth, which may be viewed by some as an opinion, but I find it to be fact: being married to me requires nothing less than absolute sainthood. Either that, or sheer lunacy - who would want to be married to someone with no control over her schedule, extreme sleep disturbances (and the coinciding mood disturbances), and the knowledge that, as long as everyone is healthy and safe at home, the needs of people outside the family will take precedence? Four years of medical school, 8 years of general surgery, and 2 years of cardiothoracic surgery training is a long time for a spouse to be patient, tolerant, and make sure that food in is the refrigerator, the bills are paid, and the dogs have been (sporadically) fed. Without a doubt, I never could have achieved my clinical and academic goals without the support of my spouse, which makes me realize, to a great extent, that I have an enormous advantage over the women out there who are trying to do it all on their own. Has my marriage been strained at times? Yes. Was it directly consequent to my job? Sometimes. (To be fair, at other times, it's just because I'm a human who makes mistakes, like anybody else.) There are the little things that can impact relationships, like saying that I'll be home in 10 minutes about 7 times in a row, until it becomes obvious that dinner is simply not happening, or falling 
asleep at the most inappropriate times. And there are also the big things: like forcing my family to move crosscountry for my training, where my husband would need to commute to a job in another city and my entire resident income (and then some) would be handed over to childcare providers. A tribute to the sacrifices of my spouse would require an entire additional issue of the journal. Let's just say, his patience and acceptance have been beyond imaginable. However, I absolutely believe that this career has had a positive impact on my marriage, as well. There are times when I can offer something to my family and friends, because of my unique experiences and knowledge acquisition, assistance that makes me feel valuable. There are moments when I see pride in my husband's eyes, and it is more validating than any other recognition in the world. And, of course, there's the old adage, "absence makes the heart grow fonder." I vividly recall the joy of celebrating our 10th anniversary together, feeling so incredibly lucky to be able to spend 3 consecutive days in the same city, eating every meal together, sleeping in the same room. The effects of this career have led me to take nothing for granted, to take joy in every moment, and to count my lucky stars on a nightly basis.

As one who identifies herself as much by the moniker "Mommy" as by "Doctor," I of course know that my career has affected my children dramatically. Even before the kids were born, this career took its toll on childbearing. My first two kids are 18 months apart, born during my research time; now, many years later, with my training completed, I am finally having a third child, and I am appropriately labeled as being of "advanced maternal age." This experience essentially sums up parenthood for women in our specialty. A national survey recently conducted and published by Pham and colleagues ${ }^{6}$ demonstrated that women thoracic surgeons tend to start families later in life than the national average, ultimately resulting in fewer children. Additionally, the study found that pregnancies among female thoracic surgeons are not particularly straightforward compared to those of their peers, and I'm a pretty good example, as a G6T1P1A3L2. (For those of you who might be a little rusty on the notation systems used to record obstetric histories, GTPAL refers to Gravida [number of pregnancies], Term births, Premature births, spontaneous Abortions [ie, miscarriages], and Live children. ${ }^{7}$ ) The dominant proposed reasons for these findings include the perception that one's career would be adversely affected, as well as the problems that are related to successful childbearing for women as they approach advanced maternal age. ${ }^{8}$ I have been blessed with amazing and healthy children, and for that I know that I am incredibly lucky.

When recently asked if they could change one thing about my job, both of my kids responded that they wished that I had more time with them. Their feelings are $100 \%$ justified. I have missed dance concerts, school breakfasts with mom, and even my own children's birthday parties (I will always feel remorse for missing my son's 5th birthday, and I will always remember the case that I was doing that day into night.) In the same conversation, my kids were asked if they would like to be cardiothoracic surgeons. Their responses were both validating and humorous. My daughter: "No, I want to be an artist. But I'm still very proud of my mommy, because she helps lots of people." From my son: "No, because I want to be daddy." Clearly, in his mind, daddies are not qualified for this job.

I know that my kids have suffered emotionally and even physically because of my job choice and my training (abridged version: dog bites on a nanny's watch while I was on-call). But I also find that, despite the snarky comments from the daycare staff and moms at the school, that there are elements of pride, lessons learned, and ways that I have inadvertently taught my kids what it means to work diligently toward a goal, to give of yourself to others, and to try to make a difference in this world.

\section{IMPACT OF PERSONAL LIFE ON A THORACIC SURGICAL CAREER \\ Single Woman's Perspective}

Many advantages come from being an unmarried surgeon; the first and foremost is sleep. I can proclaim with all the confidence in the world that I get much more sleep than Mara. My record during the fellowship period was 17 consecutive hours of sleep; I bet none of my married counterparts has ever done that. Although sleep deprivation in cardiothoracic fellows may not lead to adverse patient outcomes, ${ }^{8}$ I definitely functioned more efficiently and thought more clearly after "catching up" on sleep.

Next is exercise. This aspect of life seems to be the first sacrifice made when faced with the responsibilities of being a wife or husband, and/or a mother or father. Although I was a far cry from my half ironman days, I managed to consistently exercise several times per week, which was an excellent way to decrease stress. Given the already overly exhausting life I was living, I could not imagine dealing with the curveballs that are occasionally thrown your way when you have to worry about caring for your family in addition to yourself. Overall, I welcomed the fact that when I came home at the end of the day, I was not beholden to anything or anyone; my time was my own, and I cherished it.

These advantages are shared by unmarried male cardiothoracic surgeons. One key difference is that, in our society, unmarried men tend to be viewed as "eligible bachelors" and the term "single woman" tends to have a negative connotation. When I lived in San Francisco, I frequented the wine country, and if my friends were unable to join me, I made it a solo excursion. While I was 
discussing this outing with a male colleague one day, he said, "I can't think of anything sadder than a single 30-something-year-old woman going to Napa Valley by herself." To which I replied, "The only sad story would be that of a single woman waiting for a knight to ride up on his horse and take her to Napa Valley rather than live her life to the fullest every day." When I conferred with male colleagues, they had not found themselves in positions in which they felt they needed to defend their lifestyle. My parents, brother, sister-in-law, and close friends support both my career and lifestyle, and for this I am truly thankful.

\section{Wife and Mother's Perspective}

As a wife and a mother, for much of my training, I insisted that my personal life had no negative impact on my career. To my spouse's credit, I must admit that my marriage very rarely interfered with my ability to do my job. Occasional disagreements and interruptions happened, but they were rarely the norm. Certainly, there are others whose marriages have more significantly affected their job performance. Ample data suggest that work-home conflicts are a major contributor to surgeon burnout, particularly among female surgeons. ${ }^{9}$ Nonetheless, I still contest that I married a saint, and that my marriage has had really only positive effects on my career-a continuous supporter, someone always rooting for me, and someone taking care of the home details so I could focus on studying, case preparation, sleep, and so on.

I would also probably like to believe that my pregnancies have not affected my career at all. To some extent, I'd say it was pretty minimal. I tried to work harder and faster than the men, and I did my best not to complain, lest it would leave people the option to make such comments as "That's why we shouldn't let women into this field." I took short maternity leaves, which is consistent with the norm for women in our field. ${ }^{6}$ I have walked out of the operating room mid-case exactly once in my training, when one of my children was being taken to the emergency room and my husband was in another state. Did that one event impact my training? Not likely. However, I will be the first to admit that I showed up at in-service exams after staying up all night with febrile children, that I did some dictations from the car to make sure that I could pick up milk before the grocery store closed at 10:00 PM, and that I struggled to keep my eyes open for many more operations than would have been the case if I had not had children at home with wants and needs.

I would also be remiss if I claimed that concerns for my spouse and kids did not impact my job search and my ultimate choice in a position. However, there is a very important fact here that I never forget. I firmly believe that my family has also improved my job performance in some ways. Nothing made me work harder to save a young
TABLE 1. Tips and lessons learned to achieve work-life balance

- Maintain relationships with family and friends.

- Explore the world outside of the hospital.

- Make it work no matter what your lifestyle is.

- Show appreciation for your partner.

- Recognize that there is no "good time" for childbearing.

- Accept guilt and cope with it in a healthy way.

- Form a network of confidantes and mentors.

- Don't be afraid to ask for help.

person's life than the realization that she or he was somebody else's child. Nothing gave me greater release from the stressors of the day than the love and affection of my family, giving me fuel to return for another day. My family members have absolutely made me a better doctor, given me a better bedside manner, and motivated me to do my absolute best.

I must also mention that I have had male colleagues whose careers have also been dramatically impacted by their roles as husbands and fathers. I find it rather impossible to make any broad generalizations regarding differences between being a mother and being a father, nor is it my goal to do so. Clearly, these roles are highly variable, and they may differ in every family, based on traditions, cultural values, division of household duties, additional family support, and parental bonds. No 2 families are exactly alike, and no 2 parents are the same. While it is challenging to put into words, I do know that my parental role is a little different than those of my male counterparts - but I remain in utmost respect for their choices, their sacrifices, and the experiences that they encounter every day, as they deal with an entirely different set of societal expectations and unfair assumptions.

\section{TIPS AND LESSONS LEARNED}

We have highlighted some of the dilemmas that are faced by women in our field, recognizing that several of these issues may be relevant for all cardiothoracic surgeons regardless of gender. Thus, as we offer our insights regarding possible strategies to achieve work-life balance, we hope that many of our suggestions will be useful to our male colleagues, as well. Further, although much of our discussion has been focused on issues that arose during our training, we feel that the lessons learned will carry us through our careers. We are currently both academic surgeons, working in general thoracic practices. We are enormously grateful to our current partners for their encouragement and support, and we remain indebted to our mentors, families, and the women pioneers in our field that have afforded us the privilege of becoming thoracic surgeons. Claiming to be neither experts in women's issues, nor seasoned cardiothoracic surgeons, we offer the 
following advice, from our hearts and minds, as 2 early-career thoracic surgeons of the current era.

For single women, we offer the following advice (Table 1). (1) Make every effort to maintain your relationships with family and friends. They understand that your time is limited, but they are available if you need them and are a key source of support. (2) Find the energy to get "out and about" when you have time away from the hospital. As a single person, meeting new people and trying new adventures requires a lot of energy, because no spouse or children are pushing you to do so. (3) Realize that naysayers who disagree with your career and lifestyle choices will always be present, but being a cardiothoracic surgeon is extremely rewarding, and you can make it work no matter what your lifestyle.

For women who are trying to make it all work, with their careers pulling them in one direction, and their family pulling in the other, we will offer an opinion that, not only is it doable, but it's also absolutely worth it. We do have a few words of wisdom, lessons learned along the way. They are reflective of my experiences and observations, and, thus, are not all encompassing, but we hope that they are helpful. (1) Marry a saint. Okay, that's easier said than done, but at least recognize that anyone who wants to marry you should be treated as a saint. You may not have much time, but place quality over quantity, and treat him or her right. (2) Recognize that there is no "good" time for childbearing. Do it when you are ready, and if you are running out of time, consider options such as freezing your eggs. (3) Learn to accept your guilt. Do not try to pretend that you do not have any guilt; it is unavoidable. Just accept it, and use it as impetus to do better in the future. (4) Do not give your work less attention than it deserves. Yes, you should learn to be efficient, but do not do anything less than your best. If you are going to be away from the people you love, make it worthwhile by giving your work your $100 \%$ effort all the time. (5) Form a network of confidantes and mentors. And, finally, (6) do not be afraid to ask for help. There are people who want to see you succeed, and they would rather help you than see you fail. This may mean asking for extra time to learn a new procedure, or asking a colleague to switch call, or accepting the fact that you just may need to pay someone to clean your toilet. It's okay.

Despite the challenges, we would both choose this career again, hands down. It isn't easy, but what makes it all possible was that we support each other and appreciate both the similarities and difference in our experiences, given our personal circumstances. We have also garnered the support of mentors, co-fellows, cardiothoracic anesthesiologists, nurse practitioners, nurses, perfusionists, partners, colleagues, and the rest of our cardiothoracic surgery family. We have fostered these relationships by striving to maintain the best possible attitude in the face of sleep deprivation and stress in an overall fast-paced work environment. It has paid off, big time; as we think back to years past, most of the unfavorable memories are tucked to the back of our minds, and what stands out is the phenomenal training that we received and the camaraderie with these essential people. Finally, the importance of having women mentors in cardiothoracic surgery cannot be overstated. Being a cardiothoracic surgeon is demanding, and it is paramount to identify with a mentor who understands your situation and can help you navigate the intricate work-life balance.

\section{References}

1. Donington JS, Litle VR, Sesti J, Colson YL. The WTS report on the current status of women in cardiothoracic surgery. Ann Thorac Surg. 2012;94:452-9.

2. Shemin RJ, Ikonomidis JS. Thoracic surgery workforce: report of STS/AATS Thoracic Surgery Practice and Access Task Force-snapshot 2010. J Thorac Cardiovasc Surg. 2012;143:39-46. 46.e1-6.

3. Hartz RS. "The XX files": demographics of women cardiothoracic surgeons. Ann Thorac Surg. 2001;71:S8-13.

4. Kass RB, Souba WW, Thorndyke LE. Challenges confronting female surgical leaders: Overcoming barriers. J Surg Res. 2006;132:179-87.

5. Halperin TJ, Werler MM, Mulliken JB. Gender differences in the professional and private lives of plastic surgeons. Ann Plast Surg. 2010;64:775-9.

6. Pham DT, Stephens EH, Antonoff MB, Colson YL, Dildy GA, Gaur P, et al. Birth trends and factors affecting childbearing among thoracic surgeons. Ann Thorac Surg. 2014;98:890-5

7. Creinin MD, Simhan HN. Can we communicate gravidity and parity better? Obstet Gynecol. 2009;113:709-11.

8. Ellman PI, Kron IL, Alvis JS, Tache-Leon C, Maxey TS, Reece TB, et al. Acute sleep deprivation in the thoracic surgical resident does not affect operative outcomes. Ann Thorac Surg. 2005;80:60-4; discussion 64-5.

9. Dyrbye LN, Shanafelt TD, Balch CM. Relationship between work-home conflicts and burnout among American surgeons: a comparison by sex. Archiv Surg. 2011; 146:211-7. 